\title{
Research on Sports Tourism Image Design and Dissemination of Limiao Nationality
}

\author{
Jian Xiong ${ }^{\text {a }}$ \\ Hainan Technology and Business College, Haikou, China 570203 \\ Fund Project: Hainan philosophy and social sciences planning project (NO. HNSK (YB) 15-114)
}

\begin{abstract}
This paper adopts the methods of documentary, field investigation, logic analysis etc., and takes Hainan Li Miao nationality cultural custom, traditional sports and experiential sports tourism as research content to discuss design and dissemination of Li Miao nationality sports tourism image and puts forward workable ideas so as to provide a theoretical reference for sports tourism resources development of international tourist island.
\end{abstract}

Key words: sports tourism, image design, national culture dissemination, tourism resources development

\section{Introduction}

Located in the most southern tip of China, Hainan has more than $1800 \mathrm{~km}$ long coastline and spring season all the year, with an average temperature of $22{ }^{\circ} \mathrm{C}-25{ }^{\circ} \mathrm{C}$. Hainan has rich tourism resources of sea, sunshine, beach, forest, springs, tropical products, ethnic customs as well as the nation's marine resources which accounts for two-thirds of China. There are more than 30 nationalities in Hainan, among them the native nationalities are $\mathrm{Li}$, Miao, Hui and Han. The weather in Hainan is tropical rainforest and monsoon climate, with abundant sunshine and rain, fresh air and beautiful environment, which is a holiday resort and has more than ten million tourists both at home and abroad every year. In 2012, Hainan attracted 33,203,700 domestic and foreign tourists, with the total revenue of 37.9 billion RMB and increased $17 \%$. On January 4, 2010, the State Council promulgated "State Council's Opinions on Promoting Development of Hainan International Tourism Island", aiming to put forward general requirements of construction and development for Hainan, which contains strengthening construction of ecological civilization, enhancing the ability of sustainable development and initially building a world-class leisure and tourism resort island until 2020. The time Hainan international tourism island becomes national strategy, its sports tourism gets further development. Traditional sports activity has close relationship with Li Miao native history, custom, labor production and religious events. It has long history and rich cultural connotation. The development of Li Miao sports tourism resources can not only improve local

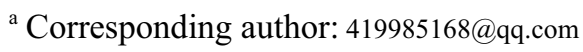

cultural heritage but also promote regional economic development, thus it worth discussing on sports tourism image design and dissemination of Li Miao Nationality.

\section{Design background of Limiao nationality sports tourism image \\ 2.1 Historical and cultural customs of Limiao nationality}

Li nationality is the first original inhabitants of Hainan. According to the exact historical records, there were Li nationality living in Hainan since pre-Qin. At that time, Li nationality belonged to a branch of Luo Yue people of hundred Yue nationalities. About five thousand to two thousand years ago, $\mathrm{Lu} \mathrm{Xu}$ took the boat across the sea. Later scattered people came Hainan from Nanyang Island and integrated into Li nationality. In the Western Han Dynasty, they were called "Luo Yue," and was called "li", and "bullying" in Eastern Han Dynasty, and was called "Li" and "Liao" in Sui and Tang dynasty. The name of "Li" began in the end of Tang dynasty and was fixed in Song dynasty, and is still in use by now. During the time of Qin and Han, the Lingao people that branched by the Zhuang nationality also entered the Hainan Island. Then Han, Miao, Hui and other ethnic groups continued to arrive here. According to historical records, the Miao nationality were not active migration but be forced to brought here. They all lived in rural areas with hard conditions. Miao ancestors has kept their toughness so that they can survive in the poor mountains and create a unique culture, which enriches the connotation of the island culture.

Li nationality is a nation that pay much attention to ceremony. Li nationality etiquette included rich contents, 
covering various aspects of production and life. Li has created live and wide range of topics and colorful oral literature, and has created more than 40 folk musical instruments with long history. Representatives of the eight traditional instruments include canoe drums, buzz wood, mouth bow, MPH blanket, beep da, mouth-Bai, nose flute and Zhuo-ba! Li nationality's songs use Fu, Bi and Xing with rich imagination, which uses language image, rigorous structure and artistic conception. Miao nationality is called "dancing nationality", the dance includes Lusheng dance, bench dance, Houer-gu dance, and the Lusheng dance is most common with high skills, which is deeply appreciated by domestic and foreign countries.

\subsection{Costumes culture of Limiao nationality}

Traditional dress of $\mathrm{Li}$ nationality has its own distinctive national style and characteristics. The main raw materials of Li nationality's colorful costumes comes from Hainan Island's cotton, linen and the like. Li's family women are with ingenuity, they can spin the wood cotton into thread, woven into cloth and dye in color and embroider with flowers. There are more than 160 species of Li's brocade fabric patterns, reflecting the Li's colorful life with rich connotations. For example, Li nationality's women in mountain area like using water deer, birds, and other animals and plants as a pattern; while women from plains love using fishes in the rive, shrimp and frogs in the pool and field egrets and other animals as brocade pattern material. "Hunting Picture" and "Wedding Picture" are representative works of $\mathrm{Li}$ nationality's . brocade. Most dress patterns are drawn from in a variety of vivid images in everyday life, which can identify race, branch and language. These image records are called "wearing epic" by the specialists.

\subsection{Sports cultural traditional festivals of Limiao nationality}

Hainan Island residents mainly include Han, Li, Miao, Hui residents, wherein $\mathrm{Li}$ and Miao are the island's indigenous people. There are 471, 500 people of $\mathrm{Li}$ nationality and 77,000 people of Miao nationality. They are located in Qiongzhong, Baoting,Baisha, Ledong, Changjiang, Lingshui, Sanya, Five Finger Mountain, Dongfang and other cities and counties. They are industrious and brave, can sing and dance. Living labor and the accumulation of wealth for thousands of years have formed a splendid traditional folk culture. Now the excellent traditional Li nationality's sports culture has been preserved include climb the perch to pass the tree, the dog to the slope, pull the tortoise, shooting, knee climbing to pick flowers, playing top, cow fighting, boat race with holding things, float match, climb the mountain to "grab the girls". These sports not only are with recreation and full of competition features; Tsien fluid double dance, Dachai dance and Dalu dance are sport projects that combines celebration, dance, fitness and entertainment. Li nationality always has the custom of dabbling leisure, and the main activities include water-sprinkling, water fights, throw water gage, tap water drum, pass water bridge, and diving etc.

March third of Love Festival is Li nationality's March Third Festival (On the 3rd of the 3rd lunar month), which is the greatest folk festivals in Hainan Province, is also a good day for Li nationality's youth. It is also know as Love Festival or Love day, and is called "Fu Nian Fu" in Li's language. Every festivals of the March Third Festival, Li and Miao residents get together in the beautiful Hainan Island with their beautiful songs and graceful dances. Men and women, the old and young of $\mathrm{Li}$ and Miao nationality are all dressed in festive costumes, and they merrily dance of the original ecological minority villages dance, and singing with $\mathrm{Li}$ and Miao's folk songs. "March Third" is the only festival to be held on behalf of the provincial government. It is stipulated by the Hainan Provincial People's Congress: "The 3rd day of the 3rd lunar month is Li and Miao's traditional festival". In the traditional March third festival, people hold Limiao's traditional sports matches, intangible cultural heritage exhibition and cruise carnival with Limiao's features.

\section{Development status of Limiao nationality sports tourism}

\subsection{Li miao nationality has rich tourism resources and great development potential}

Since the founding of Hainan province, social economy gets very fast development and the number of residents and tourists increases a lot. Government provides policy support for Hainan tourism development especially during the construction of International tourist island. Every year, the increasing tourists from home and abroad lead to the development of catering, accommodation, transportation service industries, the GDP has been increased, the employment has been expanded and the regional economy has been promoted. Improving living standards makes people gradually transfer from pursuing material culture to spiritual culture, which leads them have more demand for sports fitness, entertainment and exploration etc. People's demands for sports tourism are becoming diversified. To integrate local ethnic culture with sports tourism is a new pursuit. Hainan has the characteristics of $\mathrm{Li}$ and Miao customs culture, clothing culture, sports of traditional festival, its has rich sports tourism resources and great development potential.

\subsection{Lag of sports tourism image products development in Limiao nationality}

Although Limiao area has relatively rich sports tourism resources, it lacks of representative products, professional image production institutions, and tourism 
products with local characteristics. Traditional sports with regional characteristics have not been promoted and exhibited, clothing culture failed to get publicity, sports tourism projects have no further development, besides, sports tourism products lack of unified and standardized design and production, they fails to form a new industrial system.

\subsection{Sports tourism product design and dissemination has not been taken into account}

Although Hainan international island has become a national strategy, with large increase in foreign and domestic tourists, improvement of Gross national product (GNP) and rapid growth in regional economy. The design and dissemination of national sports tourism image have not received enough attention, which makes sports tourism on a level of simple scenic spots and natural resources. Most of them are sightseeing-type tourism products, professional tourism products with rich local characteristics and recreation tourism have not developed at all, sports culture connotation of Limiao nationality has not been explored well, and the custom national traditional sports culture and modern sports do not become two organic synthesis.

\section{Existing problems of sports tourism image design and dissemination of Limiao nationality}

\subsection{Loss of craft culture with rich national characteristics}

Limiao plastic arts has distinctive national features and it is unique national culture. But Li miao plastic arts are in danger of dying out, the existing arts are traditional costume, tools for production and living, cotton and hemp products containing coats, dresses, headscarf, cotton cloth, hemp cloth, hemp quits and hemp bags etc. The knitting technique of Li nationality is also very famous, but there is less place to inherit it. Traditional costume culture's dying out will hinder development of sports tourism. National dancing needs national costume, which can attract tourists.

\subsection{Imperfect management system, deficient in sports tourism products innovation}

Enterprise management mechanism is not perfect and there is inadequate investigation for demand of tourism products. The scale of the production enterprises is less, with decentralized management, low level and insufficient overall design and planning of sports tourism. Most tourism products are less innovate, and the artwares that can represent national features are less, recreational programs are less and tourists' degree of participation is low and the visiting time is short.

4.3 Insufficient propaganda, inadequate input of funds and lag of infrastructure construction
Tourists know very little about Hainan sports tourism, which will undoubtedly hinder development of sports tourism. Insufficient implementation rules which are in accordance with actual development of Hainan can easily bring negative effects to environment. Beside, lag of supporting facility and low level of food, accommodations and transportation will bring inconvenience to tourists in sports tourism.

\subsection{Comprehensive quality of sports tourism practitioners have not been improved}

Since the beginning of the opening up policy, political and economic culture of Hainan have gotten rapid development excepting for tourism industry image. Brand image of international tourism island has not yet been formed, with the reasons of government's imperfect management system, input has fallen short of needs, and the low quality of practitioners. The comprehensive quality of practitioners represents the image of a region and will affect the number of tourists and economic development of the region.

\section{Conclusions and Suggestions \\ 5.1 Combine Limiao traditional sports tourism to promote sports tourism}

Sports tourists have characteristics of general tourists containing property of participation and tourism as well as specificality. The culture of ethnic minorities, costume culture, food culture and traditional sports culture can be exhibited, inherited and spread through sports tourism. Future trends of tourism will pay special attention to participate nature and go back to nature. People hope to enjoy the beautiful nature scenery, to get a taste of regional ethnic culture, and especially to participate in regional minority culture and participation in local sports. Therefore, to establish some sports programmers containing recreation, ornament and local customs with regional resources in Hainan scenic spots will not only promote traditional sports and develop sports tourism but also establish the image brand of sports tourism.

\subsection{Optimize the structure of traditional sports structure of Limiao and image design}

Limiao has rich historical tradition culture, costume culture and traditional sports culture. People have created many ways to conquer nature combining with actual environment in daily living and production and have formed different styles of sport events. They have fully excavated important practical significance of traditional sports projects. Thus, we should study connotation of Limiao traditional culture and develop it into project with spread value, as well as to optimize the structure of sports project and make it suitable for mass sports participation, conducive to historical and cultural heritage and development. Thus, to increase minority sports competition and performance through improving 
sports facilities construction in tourism scenic spots and ethnic culture reserves and to make tourists involved in sports and enjoy ethnic sports will promote all-round development of minority sports tourism and lead to development of related industries to promote regional economy of related industries.

\subsection{Strengthen the construction of web advertising and sports tourism facilities, enhance Limiao sports tourism brand image}

Firstly, We can use internet propagation to help tourists know more local customs and distinctive culture, as well as to strengthen construction of sports tourism facilities so as to provide more sports fitness spots and recreation activity facilities. At the same time, we should use Limiao traditional festival to develop Limiao traditional sports, to push the combination of Limiao traditional sports and tourism and to create Limiao traditional sports band. Thirdly, we should design sports tourism sports with national features, optimize the structure and quality of sports tourism products, expand sales volume of national products and minority culture's influence, increase the diversity of products with national characteristics, to standardize price of scenic spots, to maintain a good image of international tourism island and to create Limiao sports tourism brand with the aim of developing sports tourism products of Limiao and enhance popularity and economic development drive of ethnic minority areas.

5.4 To strengthen construction of practitioner professional training and self-building, using traditional ethnic sports to shape regional image

Sports tourism contains natural resources and human resources which are full of sports elements, and it provides programs containing many services such as competition, fitness, relaxation, recreation and communication that are represented as tourism commodities. During sports tourism, it is the practitioners that makes contact with the tourists, thus the quality of practitioners will influence tourists' satisfaction to the scenic spots. Therefore, to strengthen construction of practitioners' professional training and self-building will shape regional image effectively. As the highest sports event of reflecting development of traditional minority national, minority nationality traditional sports meeting will promote minority sports significantly and contribute a lot to disseminate minority nationality traditional sports, thus it should be excavated, arranged and improved.

\section{Acknowledgement}

This research was financially supported by Hainan philosophy and social sciences planning project Foundation. (NO. HNSK (YB) 15-114).

\section{References}

[1] The State Council. "The State Council's Opinions on
Promoting Development of Hainan International Tourism Island".

http://www.gov.cn/zwgk/2010-01/04/content_1502531.ht m 2010.01.04

[2] Gao Yuanyuan, al. Research on Image Design and Communication Strategy of Sports Tourism Destination, J. Business Culture, 2010, 5.

[3] Min Jian. Sports Tourism and Its Definition, J. Journal of Wuhan Institute of P. E, 2002 (6): 4-6

[4] Wang Guizhong. Research on Classification of Sports Tourism Resources and Its Renewability, J. Sports Science, 2003, 23(4):12-15

[5] Han Zheng, al. Investigation in Tropical Sports Tourism Resources of Hainan Li nationality, J. Social Science Journal of Hainan University: 2014,32(3):126-130

[6] Xia Minhui, al. Research on Development of Minority National Sports Tourism in Hainan, J. Natural Science Journal of Hainan Normal University:2010,23(2):224-228

[7] Ma Yifang, al. Research on Minority National Sports Tourism Image Design-Take Guangxi Nationality National Sports Tourism as An Example, J. Journal of Xi an Institute of Physical Education, 2004,21 (4), 27-30. 